\title{
APLICAÇÃO DO RTQ-C COMO INSTRUMENTO NORTEADOR PARA AÇÕES E ESTRATÉGIAS DE CONSCIENTIZAÇÃO E EDUCAÇÃO AMBIENTAL
}

\author{
Jakson Nascimento ${ }^{1}$ \\ Raffaela G. de Lima ${ }^{2}$ \\ Isabela Cristina da S. Passos ${ }^{3}$ \\ Adriane Borges Cabral ${ }^{4}$
}

Resumo: O presente artigo tem por objetivo avaliar a eficiência energética de uma edificação pública de ensino à luz do Regulamento Técnico da Qualidade para o Nível de Eficiência Energética de Edifícios Comerciais, de Serviços e Públicos (RTQ-C). O levantamento de dados foi realizado através do projeto arquitetônico e visitas in loco. Estas informações foram utilizadas para gerar uma estimativa do nível de eficiência energética da edificação, utilizando a ferramenta WebPrescritivo. Espera-se que o conhecimento do desempenho energético, através da aplicação do RTQ-C, seja um importante instrumento norteador para ações de conscientização e Educação Ambiental que possam minimizar o impacto causado pela edificação e sociedade ao meio ambiente.

\footnotetext{
1 Instituto Federal de Alagoas. E-mail: jakseletricos@gmail.com. Link para o Lattes: http://lattes.cnpq.br/5713919296261274

2 Instituto Federal de Alagoas. E-mail: raffaela.germano@ifal.edu.br. Link para o Lattes: http://lattes.cnpq.br/4746557311887453

${ }^{3}$ Centro Universitário CESMAC. E-mail: isabela.arquitetura@gmail.com. Link para o Lattes: http://lattes.cnpq.br/9927185043429306

4 Centro Universitário CESMAC. E-mail: Adriane.cabral@cesmac.edu.br. Link para o Lattes: http://lattes.cnpq.br/1324515505105692
} 
Palavras-chave: Programa Brasileiro de Etiquetagem; Eficiência Energética; Edificações; Instituição de Ensino; Educação Ambiental.

Abstract: This article aims to evaluate the energy efficiency of a public educational building in the light of the Technical Quality Regulation for the Energy Efficiency Level of Commercial, Service and Public Buildings (RTQ-C). Data collection was carried out through architectural design and on-site visits. This information was used to generate an estimate of the energy efficiency level of the building, using a WebPrescritivo tool. It is expected that the knowledge of energy performance, through the application of RTQ-C, will be an important tool for awareness and environmental education actions that reduce the impact caused by publishing and society in the environment.

Keywords: Brazilian Labeling Program; Energy Efficiency; Buildings; Educational Institution; Environmental Education.

\section{Introdução}

Nos últimos anos, o nordeste brasileiro tem vivenciado uma das piores secas já registradas, com baixos índices pluviométricos, proporcionando assim uma situação considerada crítica e influenciando diretamente na disponibilidade hídrica (BEZERRA et al., 2016, p. 625). Dessa forma, há uma baixa produção das hidrelétricas e para garantir a segurança energética, normalmente recorre-se ao acionamento das termelétricas, provocando o aumento das emissões de gases de efeito estufa além do aumento do preço da tarifa de energia elétrica (HOLLANDA; VAREJÃO, 2014, p. 21).

Neste contexto, a implementação de ações que visem a eficiência energética tornou-se fundamental para o setor elétrico e para 0 desenvolvimento sustentável do nosso planeta. Pois programas que visam racionalizar o consumo de energia e água além de reduzirem o impacto ao meio ambiente, limitam o risco de interrupção de fornecimento de energia ou água e ampliam a vida útil das fontes de energias renováveis (RIOS, 2015, p.17).

Em função da construção civil causar considerável impacto ambiental, decorrente da elevada emissão de carbono durante seus processos construtivos e do alto consumo de recursos naturais finitos, surgiu a discussão referente à sustentabilidade de edifícios (SANTA et al., 2017, p. 142). Esta iniciou-se em países desenvolvidos, tais como Estados Unidos da América, onde a crise energética e o alto consumo das edificações levaram a criação de regulamentos e normas de eficiência energética em edificações (MENDES et al., 2005, p.48).

A partir de 2001, onde ocorreu uma forte crise do setor energético do Brasil, ações de racionamento de energia e investimento em campanhas que visassem a eficiência energética começaram a ser feitos (GELLER, 2003).

Com isso, em 2009 o Brasil, assim como já ocorria em outros países, 
de eficiência energética de suas edificações. Com o lançamento da Etiqueta Nacional de Conservação de Energia (ENCE), quando naquele ano foi publicado o RTQ-C, aprovado no âmbito do Programa Brasileiro de Etiquetagem (PBE). Em 2014, a etiquetagem de eficiência energética dos prédios públicos do Poder Executivo Federal tornou-se compulsória na classificação máxima, nível "A" (mais eficiente) do RTQ-C, devido à publicação da Instrução Normativa SLTI/MP № 02 de 2014 (MME, 2014, p.18).

Até janeiro de 2020, de acordo com o Instituto Nacional de Metrologia, Qualidade e Tecnologia (INMETRO) o número de ENCE's emitidas foi de 250, sendo 146 em projeto e 104 relativas a edificações construídas, das quais nenhuma destas foi emitida para edificações localizadas no estado de Alagoas, o que se apresenta como uma grande oportunidade para implementação de ações de eficiência energética nesse estado visando contribuir para avanços no tema pesquisado (PBE - EDIFICA, 2020).

Assim, este artigo tem por objetivo avaliar a eficiência energética de um edifício público de ensino, localizado na cidade de Palmeira dos Índios, estado de Alagoas, aplicando os procedimentos de avaliação descritos pelo PBEEdifica através do manual RTQ-C, com base na avaliação dos sistemas de envoltória, iluminação artificial e condicionamento de ar.

Esta análise é crucial para a adoção de medidas adequadas de intervenção na edificação, de forma a garantir melhor desempenho energético. Além disso o conhecimento do desempenho energético da edificação, através da aplicação do RTQ-C, é um importante instrumento norteador para ações e estratégias de conscientização e Educação Ambiental que possam minimizar o impacto causado pela edificação à sociedade e ao meio ambiente.

\section{Método de Pesquisa}

A pesquisa realizada neste trabalho caracteriza-se como quantitativa elaborada a partir de um estudo de caso. Realizada em uma edificação pública federal de ensino, localizada na cidade de Palmeira dos Índios, região Agreste do estado de Alagoas e inaugurada no dia 2 de agosto de 1993.

Sua estrutura é composta por dois blocos - 01 e 02 , um auditório - 03 e um canteiro de obras - 04 (atualmente desmembrado para utilização como salas de aula e laboratório do curso de engenharia civil). Os dois blocos principais, são: Bloco administrativo e o bloco de ensino, respectivamente (Figura 1). 


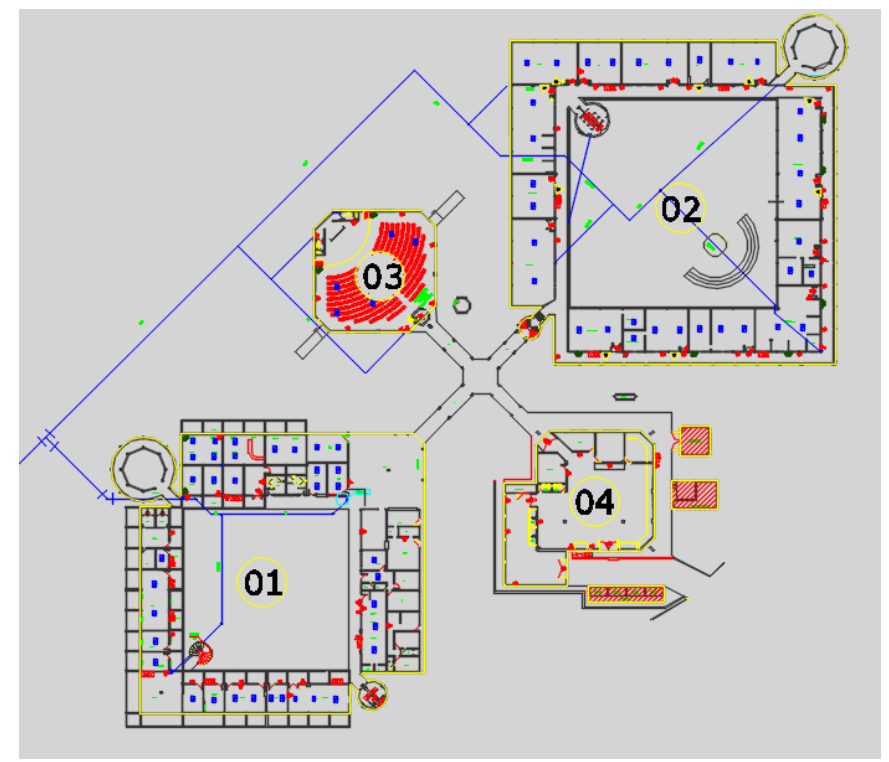

Figura 1: Planta baixa- localização dos blocos, IFAL- Campus Palmeira dos Índios.

Fonte: Autoria própria, adaptado do projeto do IFAL (2020).

A trajetória metodológica da pesquisa envolveu o levantamento de dados secundários por meio da análise das plantas dos edifícios e documentos disponibilizados pela instituição, assim como dados primários derivados de visitas in loco. As informações coletadas sobre envoltória, iluminação e arcondicionado a princípio foram analisadas individualmente e em seguida, agrupadas para classificação do nível de eficiência energética da edificação. Estas análises foram realizadas utilizado o método prescritivo, pois este quando comparado ao método de simulação, é um método simplificado, mais rápido, que atualmente possui um serviço web de avaliação, o Webprescritivo, (Figura 2) (RTQ-C, 2017, p.62).

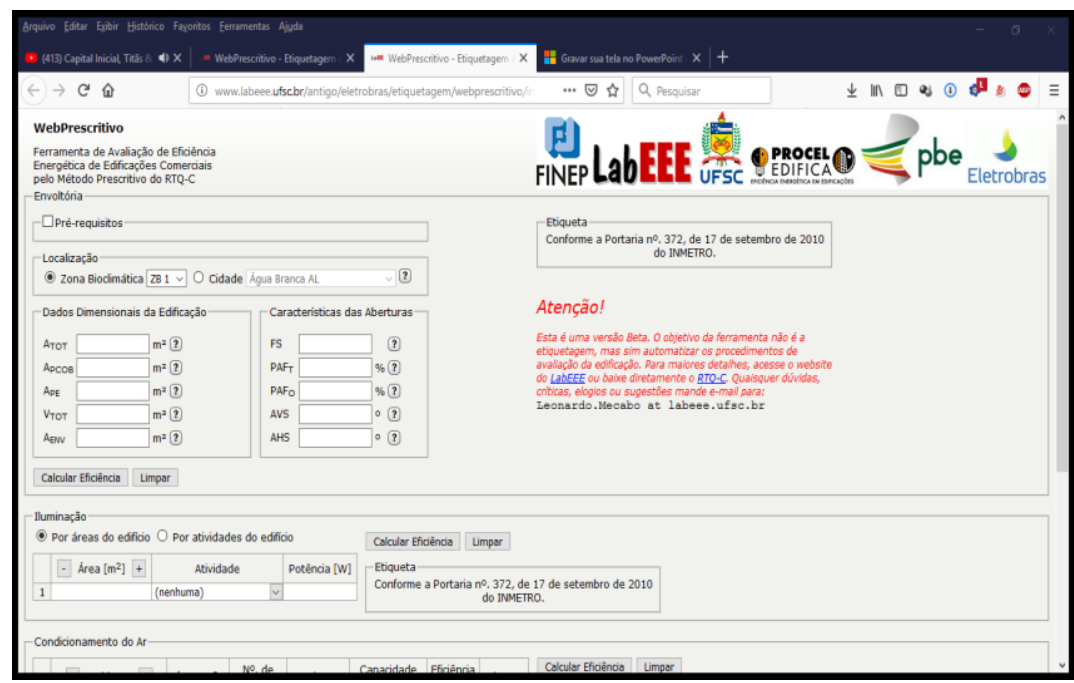

Figura 2: Serviço web baseado no método prescritivo, Webprescritivo. Fonte: Autoria própria, baseado no Webprescritivo (2018). 
A análise do desempenho da envoltória, faz-se através da determinação de um conjunto de índices referentes às características físicas da edificação. Estes compõem a "pele" da edificação (como cobertura, fachada e aberturas), e são complementados pelo volume, pela área de piso da edificação e pela orientação das fachadas (RTQ-C, 2017, p. 07). Inicialmente foi realizada através da identificação da zona bioclimática onde está localizada a edificação, com o objetivo de determinar as estratégias que um edifício deve seguir para obter o conforto térmico dos seus ocupantes. Posteriormente, sua eficiência foi obtida através de duas etapas, a primeira que compreendeu a aplicação dos pré-requisitos da envoltória: Transmitância Térmica da Cobertura das Áreas Condicionadas, Transmitância Térmica da Cobertura das Áreas nãoCondicionadas, Transmitância Térmica das Paredes e Percentual de Abertura Zenital), e a segunda etapa foi realizada através da inserção dos dados dimensionais da edificação e características das aberturas na ferramenta Webprescritivo.

Em relação à lluminação, seu nível de eficiência foi realizado com base em pré-requisitos e cálculos de densidade de potência utilizada no sistema de iluminação (DP). Os pré-requisitos dizem respeito à divisão dos circuitos, o aproveitamento de luz natural e o desligamento automático dos circuitos (RTQC, 2017, p.124).

O método utilizado para definir a eficiência do sistema de iluminação foi - Método das Áreas, este se restringe a edifícios que se caracterizam por apresentar, no máximo, três atividades e, avalia de forma conjunta todos os ambientes (RTQ-C, 2017, p.127). A edificação em análise é composta por diversos ambientes, onde foi identificada como atividades principais a função "Escola/Universidade" e "Escritório".

Para a definição da eficiência do sistema, foram realizados os seguintes procedimentos:

- Identificação da potência de iluminação de cada atividade em (W);

- Determinação da área iluminada do edifício em $\left(\mathrm{m}^{2}\right)$ e;

- Implementação dos dados no Webprescritivo.

Para determinação da área iluminada, foi utilizada a planta baixa da edificação e para a determinação da potência instalada foram realizadas visitas in loco.

No edifício em estudo, os aparelhos condicionadores de ar são todos do tipo "Split". Dessa forma, a determinação da classificação para esse sistema foi realizada com base nas eficiências individuais desses aparelhos e de suas capacidades em BTU/h. Como cada ambiente da edificação possui condicionadores de ar com níveis de eficiência distintos foram inseridos os valores de potência em BTU/h e de eficiência conforme a especificação de cada condicionador de ar presentes nos ambientes no Webprescritivo, e este 
remeteu a estimativa do nível de eficiência do sistema de condicionamento de ar do edifício.

A determinação da etiqueta geral foi definida após a determinação das etiquetas dos três sistemas individuais (Envoltória, lluminação e condicionamento de ar) e a inserção do valor estimado do Equivalente Numérico de ambientes não condicionados e/ou Ventilados naturalmente no Webprescritivo, conjuntamente com possíveis bonificações.

Este trabalho forneceu subsídios para determinação de melhorias a serem efetuadas na edificação, pois identificou-se as principais fontes de desperdícios, propondo soluções técnicas, operacionais e de manutenção para sanar os problemas.

Após a análise e tratamento dos dados obtidos nas etapas anteriores, foram verificados os pontos de maior relevância para ações e estratégias que visem aumentar a eficiência energética da edificação, pois o combate ao desperdício e a busca do uso eficiente das diversas formas de energia devem ser incentivados, principalmente em ambientes escolares, com o intuito de conduzir à economia de recursos naturais e a preservação do meio ambiente.

\section{Análise e discussão dos Resultados}

Após a inserção dos dados na ferramenta online Webprescritivo, obtevese os resultados descritos de forma resumida na tabela 1:

Tabela 1: Pré-requisitos específicos do sistema de lluminação.

\begin{tabular}{ll}
\hline SISTEMA ANALISADO & ENCE \\
\hline Envoltória & Nível C \\
\hline lluminação & Nível C \\
\hline Condicionamento de $\mathrm{Ar}$ & Nível C \\
\hline ENCE Geral & Nível C
\end{tabular}

Fonte: Autoria própria.

Os resultados apresentados permitem algumas considerações a respeito de aspectos verificados no edifício, em relação à Eficiência Energética e avaliada pelo método Prescritivo. A eficiência da envoltória foi limitada pela transmitância térmica da cobertura dos ambientes condicionados e devido a não compatibilidade do material utilizado na cobertura da edificação com a zona bioclimática 8 , além do fator de absortância das cores utilizadas nas fachadas.

Já o sistema de iluminação, recebeu esta classificação pelos seguintes motivos:

1. O pré-requisito de contribuição da luz natural não foi atendido pela edificação, pois esta não utiliza dispositivos com o desligamento das luminárias próximas às janelas, como preconiza o RTQ-C, além de possuir algumas janelas com películas que inibe a entrada da luz [Figura 3 (a) e (b)], respectivamente, e; 

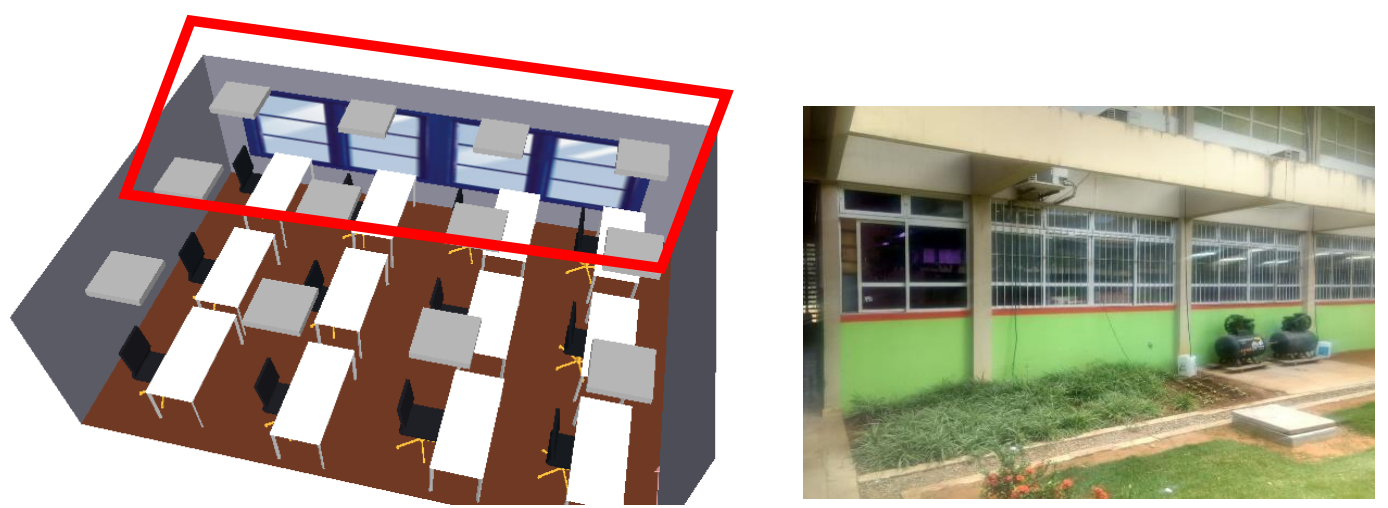

Figura 3: (a) Exemplo de circuito com controle de acionamento perto das janelas. (b) Janelas revestidas por películas. Fonte: Autoria própria.

2. Durante o levantamento de dados referentes ao sistema de iluminação verificou-se que são utilizados diversos tipos de fontes de luz artificial, são elas: lâmpadas fluorescentes compactas de 15 e 20W, lâmpadas fluorescentes tubulares de $20 \mathrm{~W}$ e $40 \mathrm{~W}$ e, lâmpadas de LEDs de 18W. Dentre estas fontes, algumas possuem uma baixa eficiência energética o que resultou em uma alta densidade de iluminação.

Em relação aos aparelhos de Ar-Condicionado verificados, em sua maioria, tem eficiência energética comprovada pelo PROCEL como B ou D, o que influenciou de maneira negativa a classificação do sistema, nível $C$, da edificação como um todo.

A edificação em análise, com suas características atuais e segundo os critérios do RTQ-C, obteria a classificação $C$, ou seja, o edifício possui uma baixa eficiência energética, como pode ser verificado na Figura 4.

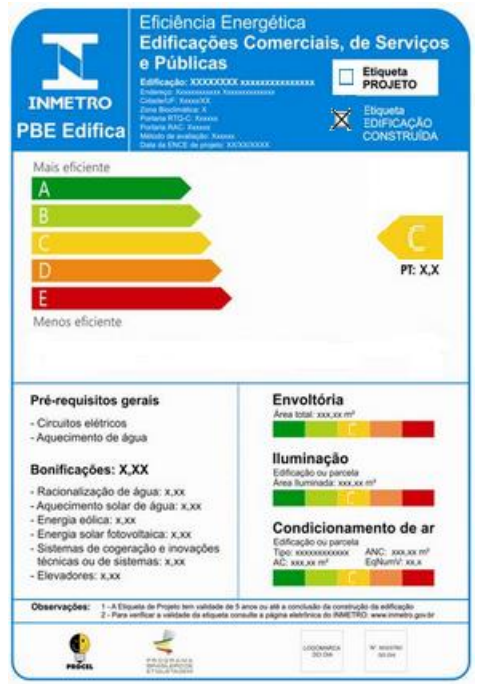

Figura 4: Etiqueta Estimada para o Edifício.

Fonte: Autoria própria, adaptada BRASIL (2017).

Revbea, São Paulo, v.16, № 1: 347-358, 2021.

revista brasileira educação ambiental 


\section{Oportunidades de Melhorias}

Para realizar a melhoria da ENCE estimada para a edificação será necessário realizar as mudanças indicadas para os sistemas de envoltória, lluminação e condicionamento de ar para que ela possa obter o nível máximo "A". Vale ressaltar que ações que visem a utilização de tecnologias capazes de tornar mais eficiente o consumo de água e energia da edificação podem elevar a classificação do prédio.

Dentre as alternativas para melhorar a eficiência da envoltória de uma edificação construída pode-se propor a troca do telhado, por um telhado compatível com as características da zona bioclimática onde a edificação está inserida, e/ou mudar o tipo de superfície das paredes, como por exemplo, pintar com cores mais claras para que assim se possa reduzir a absortância térmica ou até mesmo desenvolver teto jardim. Outra melhoria sugerida para esse sistema seria substituir os vidros que compõem grande área da fachada por modelos de alto desempenho, ou seja, mais eficientes (FERREIRA et al., 2016).

Em relação ao sistema de iluminação, uma solução seria a substituição das lâmpadas ineficientes por lâmpadas de LEDs. Pois com à crescente evolução da performance e sua disponibilização no mercado, os LEDs tornamse um produto cada vez mais atrativo. A lâmpada de LED é mais econômica quando comparada com as lâmpadas incandescente e fluorescente. Considerando o mesmo período de utilização, a lâmpada de LED, é capaz de usar apenas $6,65 \%$ de $\mathrm{kWh}$ em relação à uma lâmpada incandescente, ou seja, uma economia de $93,35 \%$ e usar apenas $28,36 \%$ em relação à uma lâmpada fluorescente, resultando uma economia de $71,64 \%$, reduzindo significativamente a densidade de potência da iluminação (DPIL) (SANTOS et al., 2015, p. 599).

Como na avaliação do condicionamento de ar, o RTQ-C, não considera a carga térmica de cada ambiente, para obter uma melhor avaliação do sistema, a sugestão seria a substituição de todos os equipamentos com baixa eficiência, por outros, com mesma potência e com etiqueta de nível A (mais eficientes). Resultado semelhante foi encontrado por Ferreira et al. (2016), que através de simulação da substituição de todos os equipamentos de condicionamento de ar da edificação por outros com etiqueta nível $A$ e consumo de energia mais baixo possível de acordo com a tabela do INMETRO, mantendo o mesmo BTU dos condicionadores atuais, mostrou que há uma economia de $12,8 \%$ por mês na edificação pública federal de ensino analisada.

Dentre as medidas que têm sido sugeridas como possíveis bonificações destacam-se o aproveitamento de água da chuva (COUTO, 2010), a implantação de sistema fotovoltaico para geração de energia e o aproveitamento de espaço ocioso com potencial de geração (ANDRADE et al., 2015), medidas efetivas e que atendem as exigências do RTQ-C para as bonificações no processo de etiquetagem de eficiência energética. 
Uma alternativa para a edificação em estudo receber bonificação na etiquetagem seria a instalação de painéis fotovoltaicos no telhado e no estacionamento da instituição. Exemplos de práticas exitosas podem ser verificadas em outras Instituições de ensino, tais como os Institutos Federais (IF's). Dentre os quais pode-se citar os Institutos do Mato Grosso (IFMT), Piauí (IFPI), Rio Grande do Norte (IFRN) e Minas Gerais (IFMG). Dentre estes destaca-se o IFRN, que até o ano de 2017 havia instalado painéis fotovoltaicos nos telhados e/ou estacionamento, capazes de gerar energia elétrica a partir da radiação solar, em 19 das suas 21 unidades de ensino (IFRN, 2017).

Apesar do grande volume de investimento inicial estima-se que em 10 ou 12 anos de funcionamento os valores economizados sejam equivalentes ao investimento, além de todo o equipamento ter vida útil de cerca de 25 anos (IFRN, 2017). Como o objeto desse estudo trata-se de uma instituição pública de educação, as usinas solares podem ser adquiridas com recursos do Ministério da Educação (MEC) através de licitação pública na modalidade de Pregão Eletrônico (IFPB, 2019).

A edificação analisada possui grandes espaços que poderiam ser cobertos com painéis para gerar energia. $O$ estacionamento e o telhado da instituição são bons exemplos, (figuras 5 e 6), pois podem gerar energia ao mesmo tempo que fornecem sombra aos veículos estacionados e conforto térmico as pessoas, respectivamente.

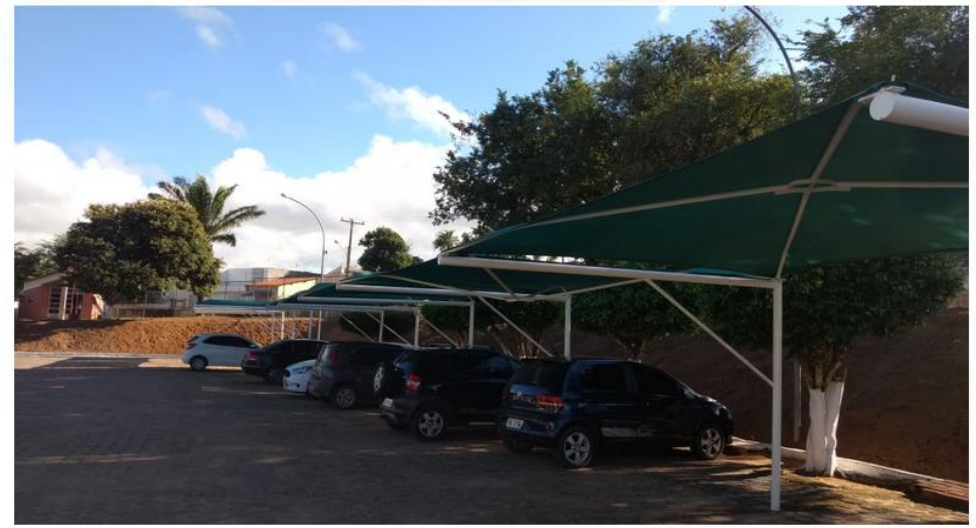

Figura 5: Estacionamento da instituição de ensino da cidade de Palmeira dos Índios.

Fonte: Autoria própria.

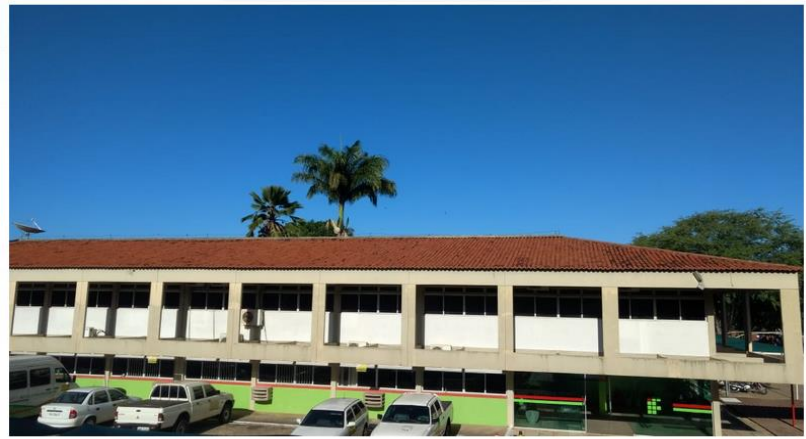

Figura 6: Cobertura da instituição de ensino da cidade de Palmeira dos Índios.

Fonte: Autoria própria. 


\section{ENCE após a realização das Melhorias}

A Etiqueta Nacional de Conservação de Energia da edificação, com suas características atuais, foi de nível $\mathrm{C}$, como verificado anteriormente na Figura 5. No entanto, verifica-se que a edificação em análise, após as alterações indicadas neste trabalho obteria a classificação A. Para isso, no mínimo, as seguintes melhorias devem ser realizadas:

- Divisão de circuitos elétricos da edificação com possibilidade de medição centralizada por uso final;

- Utilização de um sistema de iluminação que tenha um consumo, de no mínimo, 30\% menor que o atual;

- Retirada total das películas escuras das janelas e a utilização de persianas;

- Instalação de dispositivos de controle de iluminação que permitam o comando das lâmpadas próximas as aberturas, no qual será possível o acionamento da fileira de luminárias mais próximas às aberturas apenas quando necessário;

- Troca dos condicionadores de ar por outros de mesma potência, mas com eficiência Nível A;

- Instalação de um sistema solar fotovoltaico que proporcione uma economia de energia de, no mínimo, $1 \%$ do consumo atual.

Para a edificação em análise, após as alterações supracitadas serem realizadas $e$ inseridas no Webprescritivo a etiqueta geral de eficiência energética, resultou na pontuação de 4.51 , equivalente a classificação nível $\mathrm{A}$ (Tabela 2).

Tabela 2: Estimativa da classificação da edificação após as modificações sugeridas.

\begin{tabular}{ccc}
\hline SISTEMA & NÍVEL DE EFICIẾNCIA & PONTUAÇÃO GERAL \\
\hline Envoltória & $\mathrm{C}$ \\
\hline lluminação & $\mathrm{A}$ \\
\hline Condicionamento de ar & $\mathrm{A}$ & \\
\hline Etiqueta Geral & $\mathrm{A}$ & 4.51 \\
\hline
\end{tabular}

Fonte: Autoria própria.

Apesar de simples, as modificações nos parâmetros que determinam o nível de eficiência energética de dois sistemas que compõem a etiqueta geral (iluminação e condicionamento de ar) e a utilização de uma fonte de energia renovável, resultaram em uma significativa evolução na classificação geral do nível de eficiência energética da edificação que passou de "C" para a classificação máxima nível "A".

Cabe salientar que a regulamentação por si só não garante qualidade em níveis de eficiência em uma edificação, principalmente, se os usuários não tiverem participação efetiva no uso eficiente da energia, através dos seus 
hábitos. Assim todos os envolvidos na concepção e utilização da edificação e seus sistemas podem contribuir para criar e manter a edificação energeticamente eficiente. Pois uma edificação eficiente com usuários ineficientes pode tornar-se uma edificação ineficiente. Da mesma forma, edificações ineficientes podem aumentar de forma considerável a sua eficiência se houver um empenho dos seus usuários nesse sentido (RTQ - R, 2012).

Dado esse contexto, percebe-se a necessidade da instituição em análise incorporar a Educação Ambiental como instrumento dinamizador de mudanças comportamentais de toda comunidade escolar, embutindo nela a conscientização ambiental como meio de manutenção de uma sociedade sustentável não apenas para o futuro, mas no presente e de forma contínua, por isso, a Educação Ambiental deve ocupar um lugar central na promoção da eficiência energética, como conhecimento aplicado ao tratamento da questão ambiental (SILVA; PESSOA, 2011).

\section{Conclusões}

Diante do exposto, vale ressaltar que é necessário que todos os envolvidos entendam, apliquem e incorporem em suas atitudes as mudanças sugeridas neste trabalho, pois a implementação destas ações pode despertar uma maior preocupação pelas pessoas que utilizam a edificação, através do uso consciente e eficiente da energia elétrica. Neste contexto, acredita-se que a conscientização e Educação Ambiental de todos que compõem a instituição é ferramenta primordial para minimizar os impactos causados pela edificação e sociedade ao meio ambiente.

\section{Referências}

ANDRADE, J. B. S. O. et al. Future scenarios and trends in energy generation in brazil: supply and demand and mitigation forecasts. Journal of Cleaner Production, n. 103, p. 197-210, 2015.

BEZERRA, M. B.; BEZERRA2, A. P. P. S. A crise hídrica como reflexo da seca: o Nordeste Setentrional em alerta. REGNE, Vol. 2, № Especial, p. 623632, 2016.

BRASIL. ELETROBRÁS/PROCEL. Manual para Aplicação do RTQ-C. Versão 4, julho de 2017. Com base na Portaria o 372 e complementares no 17, 299 e 126, $2017 . \quad$ Disponível em: $<$ http://www.pbeedifica.com.br/etiquetagem/comercial/manuais>Acesso em: 20 de janeiro de 2019.

BRASIL. Ministério de Minas e Energia (MME). Relatório das Atividades do Comitê Gestor dos Indicadores de Eficiência Energética. Comitê Gestor dos Indicadores de Eficiência Energética (CGIEE), 2014. Disponível em: $<$ www.mme.gov.br > Relatorio+CGIEE+2014 formato+oficial.pdf> Acesso em: 20 de janeiro de 2019. 
COUTO, I. D. M. O aproveitamento de água da chuva visando a etiquetagem de eficiênciência energética em prédio comercial, Anais do Encontro Nacional de Tecnologia do Ambiente Construído, Canelas-RS, 2010.

FERREIRA, P. H. F. et al. Avaliação da Eficiência Energética do Prédio de Engenharia Mecânica da UFPA utilizando o método prescritivo determinado pelo RTQ-C. Anais do IX Congresso Nacional de Engenharia Mecânica (CONEM). Anais. Fortaleza. 2016.

GELLER, H. S. Revolução energética: Políticas para um futuro sustentável. Trad. Maria Vidal Barbosa. Rio de Janeiro: Relume Dumará, 2003.

HOLLANDA, L.; VAREJÃO, M. Energia e sustentabilidade: desafios do Brasil na expansão da oferta e na gestão da demanda. 2014.

IFPB, Instituto Federal da Paraíba. Campus João Pessoa começa a produzir energia solar. Disponível em $<$ https://www.ifpb.edu.br/joaopessoa/noticias/2017/08/campus-joao-pessoacomeca-a-produzir-energia-solar>. Acesso em: 20 de janeiro de 2019.

IFRN, Instituto Federal do Rio Grande do Norte. Sustentabilidade: Usina fotovoltaica do Campus Apodi entra em operação, 2017. Disponível em: $<$ http:///portal.ifrn.edu.br/campus/reitoria/noticias/usina-fotovoltaica-do-campusapodi-entra-em-operacao >. Acesso em: 19 de janeiro. 2019.

MENDES, N. et al. Uso de instrumentos computacionais para análise do desempenho térmico e energético de edificações no Brasil. Ambiente Construído, v. 5, n. 4, p. 47-68, 2005.

PBE-EDIFICA. Programa Brasileiro de Etiquetagem de Edificações. Edificações Comerciais Etiquetadas. Disponível em $<$ http://pbeedifica.com.br/edificacoes-etiquetadas/comercial> Acesso em 13 de fevereiro de 2020.

PBE EDIFICA. Manual para Aplicação do RTQ-R. Disponível em: $<$ http://www.pbeedifica.com.br/sites/default/files/projetos/etiquetagem/residenci al/downloads/Manual RTQR 102014.pdf> Acesso em 19 de fevereiro de 2019.

RIOS, G. A. de A. Desempenho termoenergético de habitação de interesse social. Tese (Doutorado), Universidade Estadual Paulista. Faculdade de Engenharia de llha Solteira. Área de conhecimento: automação, 2015.

SANTA, S. L. B.; ENGELAGE, E.; PFITSCHER, E. D.; BORGERT, A. Avaliação de sustentabilidade: eficiência energética em edifícios de uma universidade comunitária. Revista de Gestão Ambiental e Sustentabilidade - GeAS, v. 6, n. 2, p. $140-150,2017$.

SANTOS, T. S. dos, et al. Análise da eficiência energética, ambiental e econômica entre lâmpadas de LED e convencionais. Engenharia Sanitária e Ambiental, v. 20.4, p. 595-602, 2015.

SILVA, M. R.; PESSOA, Z. S. Educação como instrumento de gestão ambiental numa perspectiva transdisciplinar. In: NUCLEO RM NATAL: OBSERVATORIO DAS METROPÓLES. Natal -UFRN, 2011. 